\title{
EI regreso de las clases. Clase, acción colectiva y movimientos sociales Marcelo Gómez
}

\author{
Editorial Biblos, Buenos Aires, Argentina, 2014, 305 págs.
}

\author{
María Belén Morris \\ Universidad Nacional de La Plata - CONICET, La Plata, Argentina. \\ Email: belen.morris@gmail.com
}

“Aquí finaliza el manuscrito” anunciaba Frederich Engels en el capítulo 52 de El capital, justo cuando Karl Marx se disponía a especificar qué era lo que convertía a los obreros asalariados, a los capitalistas y a los terratenientes en clases sociales. Tamaña ironía de la historia la de haber legado a quienes vinieron después de Marx la responsabilidad de abordar uno de los elementos fundamentales de la teoría marxista: el problema de la conformación de sujetos colectivos y la pregunta por la forma de la conflictividad que ellos protagonizan. Marcelo Gómez se sitúa en el medio del debate para proponer un enfoque renovado que intenta amalgamar la “teoría de las clases" con las teorías sobre la acción colectiva incitando a una doble reformulación. Por un lado, la de estudiar en términos clasistas a los sectores medios rompiendo con el supuesto marxista que los define como "clases de transición" destinadas a desaparecer a raíz de la polarización capitalista; por el otro, la de potenciar los enfoques posclásicos que define como "desclasantes" anunciando el "regreso de las clases". Cómo ceder una parte para no perderlo todo es el interrogante al que el autor somete el concepto de clase y que atraviesa su obra, El regreso de las clases, donde expone el esqueleto analítico de su tesis doctoral, titulada "Asambleas barriales y ahorristas estafados, las formas emergentes de movilización de las clases medias en la crisis”.

Para que la clase pueda regresar, es preciso que antes se haya retirado. Esta es la vía de acceso al primer capítulo, "Clase y acción colectiva: enfoques y problemas teóricos”, en el que propone un recorrido por las principales tradiciones que abordaron la problemática de la clase social y la acción colectiva. Comienza analizando la "programática clásica” de la teoría de las clases, donde -en un esfuerzo por hallar sus puntos en común- sitúa a Marx y a Weber. El núcleo duro del enfoque clásico apunta a definir a las clases en función de relaciones "presociales” (p. 52) de carácter coercitivo (el lugar ocupado en la producción para el caso marxista, y en el mercado para el caso weberiano) y a concebirlas como el sujeto de cambio social. Sin embargo, reconoce allí el autor que el énfasis en la coerción estructural ejercida por dichas instancias traiciona "las promesas del concepto" en relación al “papel ‘activo’ de las clases (p. 57). 
El paso siguiente consiste en desarmar los aportes pos-clásicos de exégetas y seguidores marxistas y weberianos. Más allá de la evidente pluralidad y divergencia en las perspectivas de N. Poulantzas, E. O. Wright, el marxismo analítico, P. Bourdieu, M. Savage, R. Dahrendorf, F. Parkin y el marxismo abierto, Gómez les objeta que aunque sortearon el problema del determinismo estructural, subteorizaron el momento de la lucha y del antagonismo como elementos constitutivos de las clases.

Posteriormente, el análisis se enfoca en las teorías de la acción colectiva. El trayecto explorado abarca desde los primeros aportes (G. Le Bon, G. Tarde, H. Taine) hasta las teorías de los "nuevos movimientos sociales" de A. Touraine, A. Melucci y A. Pizzorno, la teoría de la movilización de recursos (J. C. Jenkins, S. Tarrow, D. McAdam, J. McCarthy y M. Zald) y la teoría del enmarcado interpretativo (D. Snow y A. Rivas). El balance de estas miradas arroja un aspecto positivo: la importancia que, con sus matices, asume el antagonismo en todas ellas. Pese a ello, difiere con la primera y la última en el vaciamiento del concepto respecto a su materialidad y, con la segunda, en la reducción del antagonismo a una interacción estratégica y el olvido de su carácter constitutivo para los actores. A su vez, Gómez apunta contra el efecto desclasante que opera en los tres enfoques y que se sigue de la subteorización de los intereses materiales vigentes en el nivel estructural.

En el segundo capítulo, titulado “Del análisis de clase estático al análisis clasista dinámico de la movilización social”, el autor desarma y refuta algunos tópicos propios del "análisis estático de la clase” -identificado con la "programática clásica” y con algunas de sus derivaciones- al mismo tiempo que sienta las bases para el análisis dinámico de las clases sociales que presentará posteriormente. Retomando a Goldthorpe, Gómez afirma la necesidad de abandonar la imputación automática de intereses para pasar a estudiarlos en su complejidad evitando interpretaciones mecanicistas. En esta línea, desglosa un primer lugar común, aquél que homologa la relación de propiedad a la posición y a la acción. En este sentido, sostiene que la “coerción estructural” ejercida por la propiedad no es unívoca sino multimodal y que tampoco es coercitiva sino que, entre ella y la acción, media la interpretación de los agentes. En relación con esto, aparece un segundo ítem que Gómez deshace. Se trata del “dispositivo posición-acción” que hace corresponder a la posición estructural con la acción. Este supuesto requeriría emplear la noción de interés en un sentido objetivo y negar, así, el carácter mutable al que hacía referencia en el razonamiento anterior. Luego, el autor cuestiona el vínculo “posición objetiva-conciencia subjetiva” negando tanto la correlación entre interés y conciencia como el acceso transparente de los agentes al contenido de esta última. Por último, objeta el “dispositivo reproductivista-homogeneizador” que supone el achicamiento de las distancias entre quienes comparten "coerciones estructurales" asumiendo que "las clases no se constituyen principalmente por proximidad o semejanza sino por antagonismo y lucha” (p. 126). 
Así, el autor arriba al análisis de una noción clave de su original enfoque: el antagonismo. Para pensar este aspecto, Gómez dialoga con el posmarxismo, particularmente con Ernesto Laclau. Pese a reconocer sus aportes como "inmensos y sugestivos", cuestiona que en el proyecto intelectual de repensar la política abandonando algunos vicios esencialistas de la tradición marxista y radicalizando la noción gramsciana de hegemonía, uno de los "lastres" marxistas que abandona Laclau es el concepto mismo de clase. La primera preocupación de Gómez gira en torno a lo que define como "discursivización del antagonismo", esto es, la fijación del antagonismo en el plano discursivo y el alejamiento del mismo respecto a lo "realmaterial”. A ello, opone que el antagonismo que niega la identidad está situado en la lucha y en la movilización. En sus palabras, "son las acciones de supresión material las que más contribuyen a negar una identidad y así poner en acto al antagonismo" (p. 138). Sin embargo, la relación de exterioridad que, según Gómez, mantiene lo discursivo con lo "real-material”, se pierde si entendemos, con Laclau, a lo discursivo como una totalidad estructurada de relaciones sociales siempre fallida.

La segunda objeción que Gómez plantea a la teoría de Laclau se vincula con este punto pero se sitúa en otro plano. El autor sostiene que lo "real material" o "estructural objetivo" -donde ubica a las clases y a la coerción económica - tiene un status subordinado a un ámbito "social discursivo" en la teoría de Laclau. Este elemento lo lleva a reemplazar el antagonismo de la lucha de clases por un antagonismo susceptible de hacerse presente en cualquier campo y a ponderar un carácter omnímodo del discurso que define que quien controla el discurso, controla lo real. Nuevamente, este aspecto puede matizarse si se acepta que, según Laclau y Mouffe, la distinción que Gómez identifica no es tal y que, existiendo una pluralidad de antagonismos y de puntos nodales hegemónicos, no puede sostenerse la preponderancia a priori de unos sobre otros.

Marcelo Gómez dedica el tercer capítulo a ofrecer un modo tipificado de comprender las relaciones antagónicas. Allí el autor se sirve de paratextos en los que superpone categorías analíticas con situaciones empíricas concretas asociadas a procesos de transformación de las clases medias argentinas con el objetivo de balancear el desarrollo conceptual con ejemplos ilustrativos. En el enfoque propuesto, la lucha y el antagonismo son protagonistas. Es por eso que el desarrollo se inicia con la caracterización de tres tipos distintos de antagonismo: la explotación, la opresión y la subordinación. La distinción apunta a que, por estar atravesadas por la lucha y el conflicto, las relaciones antagónicas no pueden pensarse de forma cerrada sino en su carácter cambiante y alterable. El principio específico de la organización clasista de lo social, dice Gómez, alude precisamente al dinamismo que presentan las formas antagónicas. La "lógica clasista del antagonismo" deviene central en la propuesta analítica del autor. Entiende por ella a la lucha por las condiciones materiales de existencia, sin desdeñar su impacto en el campo simbólico. En palabras del autor, "la especificidad de la lógica clasista no reside en la referencia a las relaciones 'materiales', porque si bien los antagonismos giran en torno a 'apropiaciones' de cosas, bienes 
tangibles o intangibles, lo que se pone en juego para conseguirlo es tanto material como simbólico" (p. 165).

Continuando con la lógica expositiva del autor, la dinámica de los antagonismos se desarrolla "alrededor de los intentos de establecer/mantener/aumentar/reducir/anular dependencias, reciprocidades y asimetrías en las distribuciones de bienes y recursos de todo tipo" (p. 169). Para analizar este movimiento, Gómez retoma el concepto bourdieano de capital porque le permite ampliar la perspectiva hacia los poderes extraeconómicos y multidimensionar el conflicto además de concebir a las clases como relaciones sociales. La noción es homologada a lo que el autor entiende por "poderes causales clasistas", cuyas propiedades son contingentes y son el objeto mismo de las luchas. Con esto, consigue superar la idea de que en las lucha de clases hay una "lucha cuantitativa por el volumen del capital" (p. 178) y ubica la disputas en las propiedades estratégicas del mismo.

El desarrollo se traslada, luego, al estudio de los distintos poderes causales clasistas. Estos son clasificados de acuerdo a su relación con el contexto en poderes monádicos independientes o primarios y poderes posicionales o secundarios. Dentro del primer grupo, ubica al capital económico y al capital educativo, cultural y simbólico -este último, de suma relevancia para el estudio de las clases medias-. Por su parte, entre los poderes causales posicionales y organizacionales (aquellos que deciden sobre las condiciones de ejercicio de los poderes causales restantes) ubica al capital burocrático y a capital social y político. Respecto a este último, al que define como el poder de influencia sobre las decisiones, Gómez sostiene que "desde el punto de vista del fuerte, la política es hacer aceptar al débil las relaciones de poder dadas (...) [mientras que] la del débil siempre es una política afirmativa, una política de la necesidad de un tipo de acción específicamente orientado a alterar distribuciones y valores económicos, sociales, culturales y simbólicos” (p. 205-206). Pareciera colarse aquí un supuesto del análisis estático de las clases que el autor se había dispuesto a eliminar; aquel que traza un vínculo unidireccional entre la posición del agente y su acción mediando entre ellos un "interés" objetivo que impide analizar la disputa por las propiedades estratégicas de los poderes causales clasistas.

No obstante, el minucioso examen que Gómez realiza de las instancias de mediación y activación de los poderes causales reintroduce el dinamismo característico de su enfoque. Este es el objetivo manifiesto del cuarto y último capítulo, titulado "La movilización social como proceso clasista”. Allí el autor estudia el movimiento de propiedades estratégicas involucrando dos planos: el primero, individual, corresponde al proceso de activación y conversión de los poderes causales en términos absolutos y en términos relativos -es decir, en relación a los poderes causales antagónicos-; el segundo, colectivo, se vincula a la movilización y colectivización de dichos poderes. La primera dimensión enfatiza en aquello que se hace con lo que se tiene y distingue algunas posibilidades de conversión: fuerza de trabajo-capital económico, fuerza de trabajo--educación, propiedad eco- 
nómica-poder posicional, poderes cultural, simbólico y educativo-poder organizacional. La conclusión de este apartado apunta a la centralidad del capital económico en tanto "poder simultáneamente posibilitador y activador-mediador del resto de los poderes” (p. 235).

En la segunda sección del capítulo, destinada a pensar la colectivización de los poderes causales, Gómez teoriza acerca de la relación entre intereses individuales y colectivos y sostiene que dicho vínculo es resultado del antagonismo debido a que los poderes causales son necesariamente comparativos. En esta dirección, apunta que la colectivización de los mismos sigue a la insuficiencia de colectivos disponibles para superar asimetrías, dependencias y adversidades y que ello desata formas de colectivización novedosas. Luego, el autor analiza algunas de las contradicciones que conlleva un proceso de colectivización a raíz de los poderes causales individuales que allí convergen y que habilitan u obstaculizan la movilización. También subraya el carácter clasista de los repertorios de acción marcando la diferencia entre aquel que impera en las movilizaciones de clases medias (el escrache) y el de los trabajadores desocupados (el piquete) entre 2001 y 2002 destacando la moralización de categorías empleadas para definir uno y otro. Para finalizar, dedica unas líneas al estudio de los “efectos de poder" que producen las colectivizaciones distinguiendo, de acuerdo a su capacidad de intervención sobre el orden social, al poder situacional del institucional y del sistémico. La acción colectiva contenciosa, dice el autor, "supone convertir en situacional lo que para los actores poderosos es materia institucional o sistémica (...) asume la forma de ‘develamiento’, de desnaturalización y desocultamiento de la invisibilidad de los modos de imposición institucionales y clasistas” (p. 268).

Las conclusiones del texto sintetizan el laudable esfuerzo por rescatar la potencialidad analítica de la clase proponiendo un concepto "recargado”. En él, se reniega de la coerción estructural y del interés como elementos explicativos de la clase y se rechaza la definición de la clase como grupo privilegiando su análisis como forma de organización de la diferencia y del antagonismo que remite a las condiciones materiales y que exhibe emplazamientos constantes. También se desdeña el supuesto economicista que define las luchas clasistas como luchas por el incremento del volumen del capital. Por el contrario, la tesis del autor se asienta en la definición de las clases a partir de la lucha y el antagonismo "real” y "material” y de la acción clasista como aquella que se ejerce con el objetivo de incidir sobre la distribución de los poderes causales. La mixtura de luchas, antagonismos, sincronías y diacronías que Gómez propone en El regreso de las clases. Clase, acción colectiva y movimientos sociales brinda un sugerente potencial explicativo para las sociedades en movimiento. Por otra parte, el esfuerzo por recuperar a las clases sociales de su muerte epistemológica, filosófica-ideológica e histórica-social -tal como expresa al principio de su obra- mediante el desarrollo de un enfoque exhaustivo y profundamente analítico permite una mirada particular de los movimientos y colectivos en su especificidad pero también su reinscripción en la totalidad relacional y conflictiva que les da sentido. 